\title{
ENTRE A TERRA E O CÉU GUARANI: UMA CONVERSA COM B. MELIÀ
}

DANIELLE BASTOS LOPES ${ }^{1}$

UERJ

De acordo com Bruno Latour (1991, p. 9), "nós mesmo somos híbridos, instalados precariamente no interior de instituições científicas". Foi, portanto, partindo deste princípio híbrido, precário das instituições, me valendo entre uma mescla-escala de campos, tanto da etnologia quanto da Educação, mais precisamente de uma mescla entre campos do currículo e das cosmovisões, mundos sobre-humanos dos Guarani, que, na época de minha conclusão de doutorado, lancei-me em uma desafiadora tentativa de releitura e entrevista das obras de Bartomeu Melià. A entrevista aqui descrita inicia-se no ano de 2014, na época de uma visita de Melià ao Brasil, e é amadurecida e revisada pelo autor em finais de 2016. Bartomeu Melià Lliteres é um dos maiores, se não o maior, etnólogo especialista das sociedades guarani durante o período colonial luso-hispânico e época contemporânea. Nasceu em Porreres, na Espanha, em 1932 e em 1954 radicou-se no Paraguai, onde iniciou seus estudos da língua e cultura guarani tendo o padre Antônio Guash como primeiro professor. Partindo de uma análise de entrevistas, algumas antigas e outras mais recentes, e obras editadas recentemente, o exercício desta entrevista foi o de atualizar o leitor em uma variabilidade de campos da antropologia influenciados por Bartomeu Melià, mais especificamente por suas análises do campo da educação e escolarização indígena. A intenção não foi tanto a de esgotar as

\footnotetext{
${ }^{1}$ É professora da Universidade do Estado do Rio de Janeiro (UERJ). Doutora em Educação e mestre em História Social pela mesma universidade. Coordenadora do projeto Pensando Culturas Ameríndias no Cap/UERJ. Suas pesquisas concentram-se nas sociedades mbyá-guarani, com interesse em assuntos de currículo, escolarização indígena e cosmologia. E-mail: daniellebastoslopes@ hotmail.com .
} 
possibilidades de releitura das obras de Melià, mas de oferecer ao leitor um frescor do que vem sendo discutido, revisitado e avaliado pelo autor em relação a suas novas obras até o momento.

Danielle: Atualmente, no livro El Mundo Guarani, o senhor produziu um mapeamento das literaturas que discorrem sobre os povos Guarani e os seus principais pesquisadores. Poderia explicar um pouco sobre esse trabalho de mapeamento dos autores que dissertaram sobre os Guarani e os pontos que achou mais marcantes dessa extensa bibliografia?

Melià: A bibliografia data de 2006, entretanto, atualmente devem existir muitas novidades e literaturas recém-escritas. Em princípio, esse livro foi feito sob encomenda. Tínhamos que colocá-lo o mais próximo quanto possível da literatura sobre os povos Guarani. Foi preciso dividilo entre a antropologia guarani e outra bibliografia, mais própria das especificidades do campo linguístico. Entre os autores mais importantes estão Curt U. Nimuendaju, León Cadogan e Egon Schaden. A respeito dos Paĩ-Tavyterã, tínhamos o trabalho do doutor George Grünberg e de sua mulher, Friedl. Havia contribuições muito importantes que agora não estou recordando; muitas foram relevantes, tanto no conjunto quanto em aspectos que devemos ter presentes na etnologia. Destacam-se artigos, por exemplo, como o O Canto Largo, a respeito dos Paĩ-Tavyterã, recolhido por Marcial Samaniego, posteriormente melhor editado por Cadogan.

Danielle: Em entrevista ao Instituto Humanitas de Ensino em 2010, o senhor relatou: "Minha experiência começa em 1969, quando entrei em um lugar do Caaguazú, de cujo nome sempre me lembro, Mbarigui, é até hoje um lugar onde as famílias guarani-mbyá estão morando em plena selva". O senhor conviveu com as sociedades ali presentes desde 1969; o que lembra de mais marcante dessa convivência? 
Melià: Sim, no departamento de Caaguazú, no km 225 da estrada Ciudad del Este.

Danielle: Refere-se "[...] de cujo nome sempre me lembro, Mbarigui [...]."

Melià: Mbarigui [corrigindo a pronúncia da entrevistadora] corresponde a um espécime de inseto que pica e deixa numerosos pontos vermelhos no corpo e pequenos pontos de sangue. Na região, havia famílias guarani, que atualmente vivem entre plantações de soja. Durante aquela época, com este grupo em específico, meu convívio deu-se de forma muito irregular; não residi no local por longos períodos. Em relação aos Mbyá, o mais marcante foi quando me aceitaram na opy (casa de rezas). Este momento representou um fato profundamente marcante. Posteriormente, me marcou a vivência cotidiana com eles, o dormir no chão, o aquecer os pés junto ao fogo, caminhar com algum deles rente ao mato, percorrer o trilho das armadilhas, todo esse cotidiano me marcou. Mas, naturalmente, o mais impressionante foi a participação nos rituais, muito frequentes na opy.

Danielle: Havia escola?

Melià: Não, nem pensavam em sua possível existência.

Danielle: Sua tese sobre a língua cristã-guarani nas missões jesuítas no Paraguai é de 1969. Atualmente o que destacaria de contribuições desta pesquisa, pensando nas obras que tem desenvolvido até aqui?

Melià: $O$ título da tese, numa tradução do francês para o português, é $A$ criação de uma linguagem cristã nas missões dos Guarani no Paraguai. Essa tese abriu para nós um caminho um tanto profético; de fato porque eu estava trabalhando com documentos antigos que falavam dos Guarani, mas eu não os conhecia. Apenas quando eu regressei ao Paraguai, posteriormente à tese, é que fui me aproximar do que poderia ter sido a criação de uma linguagem cristã a partir da religião guarani. As fontes coloniais sobre religião guarani, de fato, são muito escassas. 
Danielle: Em relação à cosmovisão e cosmologia há muito pouco?

Melià: Sim, é muito escassa a bibliografia. O Montoya, no capítulo 10 da Conquista Espiritual (MADRID, 1639), tem uma boa descrição, mas não há muito mais do que esse material. Quando entrei em uma opy e fui conhecendo os Mbyá-Guarani, entendi alguma coisa do que as tais fontes coloniais estavam apenas insinuando, eu pude perceber que na realidade trata-se de uma religião muito viva, atual, mesmo para aqueles que, ao que parece, estão se afastando dela.

Danielle: Em outra entrevista, à Revista Mana, em 2013, o senhor relatou que "Primeiro foram comunidades mbyá. Minha entrada ocorreu graças à ajuda do Cadogan. Posteriormente, o caminho ficou mais fácil, nas visitas a comunidades localizadas na área dos 'padres do verbo divino'. Foi quando tive maior contato com os Avá-guarani, mas quase não tenho anotações oriundas destas experiências, nunca levei um diário de campo." Gostaria que falasse um pouco mais sobre essa experiência.

Melià: Eu praticamente não tinha contato com os padres. Tornei-me muito amigo deles, mas não foi através deles que entrei nas comunidades avá-guarani. Diria que eles me introduziram indiretamente.

Danielle: Eram os Avá-Guarani, Ñandéva?

Melià: Sim, Avá-Guarani, naquele tempo denominados também Chiripá; no Brasil, designados como Ñandéva.

Danielle: O que destacaria dos Mbyá em relação a outros povos?

Melià: Entre os Mbyá é muito característica a centralidade da opy. Não é uma religião aberta como a dos Avá-Guarani, onde uma pessoa estranha, às vezes até mesmo os paraguaios, podem participar. Os Pãi, os Kaiowá no Brasil aceitam também em algumas circunstâncias a presença de estranhos. A opy, para os Mbyá, faz parte de uma religião 
de caráter profético; centra-se no canto e na dança sobretudo. Ambos são muito intensos.

Danielle: Quais seriam, então, algumas das particularidades entre os Mbyá e outros grupos Guarani?

Melià: Uma característica muito marcante e muito produzida para o exterior são as cestarias, por exemplo. Nos três grupos elas são muito distintas entre si: há o ajaká, o ajo e o minaku. Outro fato particular corresponde à fonética: o modo de falar, o sotaque, são muito característicos, com fonemas diferenciados. Entretanto, estamos em um momento, atualmente, em que muitos deles dominam o idioma paraguaio. O perigo não é tanto que eles falem também o guarani paraguaio; o perigo é o desuso e a vergonha de oralizar-se em sua própria língua.

Danielle: Ainda aproveitando o relato descrito na Revista Maná em 2013, quando afirma: "À 'terra sem mal' será conferido um sentido de paraíso na Terra, de ressonâncias quase bíblicas, quando, para os Guarani, esta terra é um lugar onde se dão as condições de uma autêntica economia de reciprocidade, que permite o dom e a igualdade." Gostaria que falasse a respeito dessa múltipla interpretação e das divergências acerca do conceito de "terra sem mal", principalmente quando destaca que muita gente tem exaurido o assunto sobre esta "Terra".

Melià: O Nimuendajú tratou deste assunto como uma hipótese a partir dos Avá-Guarani, ou Ñandeva, os denominados como Apapocuva, "aqueles de arco comprido". Porém, o Mbyá sempre fala que tal conceito é uma bobagem. Os Mbyá possuem outro conceito semelhante, mas também diferente; denominado de $Y_{v y j u}$, que significa boa terra, terra áurea, mas não necessariamente se trata de uma terra que vão procurar. O curioso desse conceito de "terra sem mal" é que ela tem tido uma acolhida quase que exagerada por parte de nossa sociedade, que viu nela uma espécie de fusão mítica. Uma fusão dos nossos ideais: o "nosso" paraíso cristão, no céu, e a ideia de uma terra sem mal nesta terra... 
Danielle: A respeito da sua relevante contribuição sobre a concepção de tekó porã ("bem-viver") e tekohá ("lugar"/"território") como conceitoschave do pensamento e habitualidade guarani; para algumas leituras, o senhor chegou a ser até mesmo acusado de inventar ou superestimar a centralidade desses conceitos. Gostaríamos que falasse um pouco a respeito.

Melià: Tekó porã. Dentre os tekó faço uma diferença cada vez mais profunda entre o tekó porã e o tekó katú. O tekó katú corresponde ao autêntico, seria como um "modo de ser" legal e próprio, quase como um sistema de leis, uma constituição não escrita, uma reta consciência. $O$ tekó porã, por sua vez, refere-se ao bem-viver e o tekó marangatu, ao modo de ser religioso. A partir desses tekó é que se origina o tekohá. Sobre o tekohá, tenho escrito alguns trabalhos que identificam o tekohá como território cultural, o lugar que produz e onde se produz um determinado modo de ser que é o guarani: "sem tekohá não há tekô". Portanto, o importante para o Guarani não é um pedaço de terra, mesmo muito grande, mas uma terra que assegure as condições do bem-viver, do tekó porã.

Danielle: O que pensa da ideia de superestimar o conceito?

Melià: Na Antropologia somos todos tradutores, e temos boas e más traduções. Então, a boa tradução é aquela que brevemente não fala o mesmo nome, não corresponde a uma transcrição literal do conceito antigo, do conceito guarani, entretanto, nos dá a entender, não somente pelo conhecimento, mas pela sabedoria e pela emoção, um conceito indígena. É uma técnica relativamente válida, isto é, podemos entrar em diálogo com essas culturas, mas também não entramos inteiramente nelas.

Danielle: Entrando na questão da educação, Educação indígena $e$ alfabetização é um livro que surge de um trabalho coletivo, feito a partir de uma grande equipe e em boa parte produzido no Mato Grosso, realizado por volta de 1978. Gostaríamos que falasse um pouco sobre 
esta experiência: como foi a ideia, o processo e o que mudou de 1978 para cá? O que destacaria em relação à educação indígena daquele livro para agora?

Melià: Foi um trabalho pioneiro no Brasil, apenas Silvio dos Santos produziu um trabalho um pouco diferente. Esta obra representa a primeira síntese da educação indígena que tivemos no Brasil. Tal feito foi possível, em grande parte, pela minha experiência no Paraguai com os Guarani. Naquele momento eu tinha sido exilado, no ano de 1976, e o livro foi editado no ano de 1978. Tive a sorte, pois havia nas palestras e discussões um secretário excelente que a cada dia transcrevia todo o falado, em seguida corrigíamos, pouco depois o livro estava concluído. Penso que há muitas boas intuições nessa obra, que não são só minhas, mas também de pessoas que trabalhavam com grupos Xavante, Bororô, Mỹky, Iranxe, Munduruku, Kayabi, Rikbaktsa...

Danielle: O livro sobressalta as particularidades e o perigo da "diglossia" ante os sistemas e políticas de educação ainda nos anos 1970. O que destaca a respeito desta questão da diglossia?

Melià: Este termo eu cheguei a conhecer casualmente a partir da obra de um escritor catalão em 1972. A diglossia é exatamente o que está acontecendo no Paraguai. Há até o momento um abismo linguístico entre o guarani e o espanhol, entre dominado e dominante; o bilinguismo paraguaio é, em verdade, diglóssico. A diglossia permeia e atravessa todas as situações cotidianas. Penso que aqui, no Brasil, a população está vivendo em uma marcada situação de diglossia. Às vezes as que nós chamamos de pessoas "do povo", estas não entendem uma lei, não conseguem compreender um jornal, por exemplo, mas mantêm viva a língua. É notório que a própria educação está incentivando a diglossia. As classes sociais são classes diglóssicas.

Danielle: Gostaria que falasse um pouco mais a respeito da relação educação e bilinguismo, tendo em conta a declaração contida no livro Passado, presente y futuro da lengua guarani (2010), de que o bilinguismo abafa a questão da diglossia. 
Melià: Muitas vezes a língua considerada inferior, de fato, é culturalmente a mais criativa, aquela que mantém a língua como expressão de um modo de ser mais amplo. Nós não oralizamos como a emissora Globo ou a revista Veja, nós falamos como o povo; somos praticamente como eles. Às vezes temos, e é muito legítimo que tenhamos inveja desse linguajar do povo. Trata-se de um linguajar que é muito mais rico e simpático do que aquele da elite.

Danielle: Atualmente a Unesco tem expressado que uma das questões marcantes sobre a educação indígena são os diferentes e em parte divergentes significados que o termo "interculturalidade" tem adquirido. Com base nas crítica e questões levantadas no seu livro Passado, presente y futuro de la lengua guarani (2010), gostaríamos que falasse a respeito da interculturalidade.

Melià: Interculturalidade é um termo conceitualmente bom, um conceito válido; entretanto, muito enganoso. Por que enganoso? Porque falamos de interculturalidade e de fato nós oferecemos ao negro, ao índio, ao Outro, oportunidades para que estes possam cursar a nossa cultura, isto é, levamos o que nós consideramos médio ou inferior para eles. Oferecemos fórmulas para assimilar o outro ao nosso modo de ser e isso chamamos de interculturalidade. Não se trata de um verdadeiro ato de escuta do outro; apenas possibilitamos um diálogo conosco, mas não estamos prontos para ouvir. Interculturalidade seria nós dialogarmos também com eles, precisaríamos escutar o outro, mas tal fato não acontece. Interculturalidade não é abrir o caminho para o índio aprender português; interculturalidade seria o Brasil inteiro saber uma língua indígena pelo menos. Se de fato existisse interculturalidade, a nossa própria mentalidade aceitaria outros sistemas de vida e outros costumes. Nesse sentido, o índio é muito mais aberto, mais intercultural, porque facilmente passa a nos entender, mas nós dificilmente o entendemos. Se a discriminação continuar, não teremos dado o menor passo em matéria de interculturalidade. 
Danielle: E quanto aos cursos de formação de professores indígenas, o que tem observado? Qual a sua opinião sobre estas políticas?

Melià: Em alguns casos a formação docente me parece um modo de afastá-los de sua própria comunidade. Mas há casos em que realmente os Guarani são muito conscientes e mantêm a própria cultura. Estão fortalecendo a mesma sem deixar de ter um novo instrumento, como a escola. Espero que esses docentes não substituam a educação formal guarani pela escola. Isto seria desintegrar o índio, o que está acontecendo em muitos casos.

Danielle: A Unesco discorre sobre o fato de que a maioria dos países tem uma planificação nacional de currículos para educação indígena, uma legislação de currículo nacional específica. Eu pediria que falasse um pouco sobre a ideia de legislação de currículo, de uma planificação nacional de currículo para as populações indígenas.

Melià: Em relação à Unesco, seus membros intelectualmente querem recuperar os saberes indígenas, querem resgatar a identidade desses povos; entretanto, a UNESCO atua concretamente em diversos países onde, digamos, o elementar da interculturalidade não é compreendida. Muitos desses países têm uma visão muito colonial, ou seja, uma só língua, um só direito, uma economia; não estão abertos à interculturalidade de fato; são ainda coloniais, sendo eles mesmos colonizados.

Danielle: Gostaríamos que falasse um pouco também sobre a planificação nacional de currículo diferenciado, intercultural e bilíngue para as escolas indígenas, o que tem ganhado relevo em extensa parte da América Latina.

Melià: O currículo nacional visa uma educação para pobres, disponibiliza uma educação para pobres; mas, de fato, esses povos são ricos em cultura e chegam à escola com uma bagagem cultural enorme, pois foram educados desde o momento de nascer, desde o momento da 
concepção. Se os recursos da educação nacional forem pobres, os docentes oferecerão uma pobre educação, descartável e sem horizonte.

\section{Referências bibliográficas}

LATOUR, Bruno. Nous n’Avons Jamais Été Modernes. Paris: Découverte, 1991.

MELIÀ, Bartomeu. Educação Indígena e alfabetização. São Paulo: Loyola, 1979. . (Org.). Os Guarani: palavra e caminho. Revista IHU On-Line, São Leopoldo, v. 10, n. 331, 2010a.

. Passado, presente $\mathbf{y}$ futuro de la lengua guaraní. Asunción: CEADUC/ISEHF, 2010b.

Mundo Guaraní. Asunción: BID, 2011.

. Palavras ditas e escutadas. Mana, Rio de Janeiro, v. 19, n. 1, p. 181-199, 2013.

Recebido em: 10/12/2016 * Aprovado em: 21/12/2016 * Publicado em: 31/12/2016 